\title{
DESENVOLVIMENTO DE PESSOAS EM UM MICRO EMPREENDIMENTO DO TERCEIRO SETOR: A EXPERIÊNCIA DA ADESJOVEM
}

DEVELOPMENTOFPEOPLEINAMICROENTERPRISETHIRDSECTOR:THE EXPERIENCE OF ADESJOVEM

\section{Robson Malacarne}

rrobson.malacarne@ifes.edu.br

Instituto Federal do Espírito Santo-Vitória -ES- Brasil

\section{Janette Brunstein}

janette@mackenzie.com

Universidade Presbiteriana Mackenzie - São Paulo - SP-Brasil

\section{Margarete Dias de Brito}

marga.d@hotmail.com

Universidade Presbiteriana Mackenzie - São Paulo - SP-Brasil

\section{José Luiz Bedoni}

joseluizbedoni@gmail.comrodrigonascr@hotmail.com

Faculdade Pio XII - Cariacica - ES-Brasil

\section{Rodrigo Nascimento Rodrigues}

rodrigonascr@hotmail.com

Instituto Federal do Espírito Santo-Vitória -ES- Brasil

\section{Resumo}

0 objetivo deste estudo é compreender as ações de desenvolvimento de pessoas da ADESJOVEM. A experiência do micro empreendimento social é singular, pois sensibiliza e envolve profissionais de diferentes áreas do conhecimento para atuarem com projetos de Desenvolvimento de Competências Empreendedoras - DCEs. Destaca-se, neste processo, o Programa de Incentivo a Inovação Social, Inova Jovem, e o Projeto de Educação Empreendedora, A Juventude Quer Mais. 0 desenvolvimento teórico se fez com base nas reflexões sobre gestão de pessoas de Davel e Vergara, nas competências preconizadas por Wiek, Withycombe e Redman e na discussão de Aprendizagem Social de Elkjaer. A pesquisa foi feita a partir das entrevistas realizadas com a diretoria e com os beneficiários dos projetos desenvolvidos pela entidade. A análise dos dados revela que o incentivo a inovação é uma estratégia que favorece $o$ DCEs, principalmente quando associada a projetos participativos e cooperativos.

Palavras-chave: Desenvolvimento de Competências Empreendedoras. Terceiro Setor. Empreendedorismo Social. Gestão de Pessoas. Aprendizagem Social. 


\title{
Robson Malacarne, Janette Brunstein, Margarete Dias de Brito e José Luiz Bedoni, Rodrigo Nascimento Rodrigues
}

\begin{abstract}
The objective of this study is to understand the actions of people development ADESJOVEM. The experience of micro venture is unique because it sensitizes and involves professionals from different fields to work with projects Skills Development Entrepreneurs - SDE. It is noteworthy, in this case, the Incentive Program for Social Innovation, Youth Innovation and Entrepreneurship Project of Education, Youth Want More. The theoretical development is made on the basis of reflections on people management of Davel and Vergara, skills advocated by Wiek, Withycombe and Redman and discussion of Social Learning Elkjaer. The survey was taken from interviews with the directors and the beneficiaries of the projects developed by the entity. Data analysis reveals that encouraging innovation is a strategy that favors the SDE, especially when associated with participatory and cooperative projects.
\end{abstract}

Keywords: Entrepreneurial Skills Development. Third Sector. Social Entrepreneurship. People Management. Social Learning.

\section{Introdução}

As organizações do terceiro setor, constantemente, reproduzem modelos de gestão adotados nas grandes empresas, sem considerar as singularidades do público destinatário de suas ações. Um dos objetivos desta prática é a busca de uma imagem junto ao mercado, de instituição eficiente e eficaz, que adota ferramentas consagradas na iniciativa privada, de modo a facilitar a captação de recursos junto aos órgãos de fomento e as fundações empresariais (RAMOS, 1989). No caso de micro e pequenas organizações não governamentais a dificuldade se repete, os modelos de gestão disseminados nas publicações voltadas para este setor, geralmente, não consideram as especificidades destes pequenos empreendimentos.

Ainda que o desenvolvimento de modelos de gestão alternativos enfrente dificuldades nas micro e pequenas organizações, observam-se exemplos de iniciativas que ousam criar seus próprios modelos, algumas destas ações são experimentadas no trabalho realizado com as juventudes. Isto ocorre devido a característica dos sujeitos envolvidos nestes projetos, marcado pela diversidade de comportamentos, perspectivas e formas de socialização (GROPPO, 2000). Enfatiza-se que no Brasil, a partir do Estatuto da Juventude, considera-se jovem os sujeitos que se encontram na faixa etária de 15 a 29 anos. As entidades que trabalham com este grupo são provocadas a criar estratégias de ação inovadoras e flexíveis de modo a promover o desenvolvimento de competências empreendedoras nestes indivíduos. Como exemplo de entidades que trabalham com este foco, podemos citar as incubadoras de empresas, as empresas juniores, os centros de empreendedorismo, e as entidades vinculadas a Confederação Nacional de Jovens Empreendedores - CONAJE.

Estas organizações do terceiro setor fazem parte de um movimento de empreendedorismo juvenil voltado ao desenvolvimento de competências empreendedoras, este objetivo é alcançado por meio da realização de seminários, campanhas e projetos de capacitação, na qual a vivência e a prática se constituem como as principais estratégias de aprendizado. Nesse sentido, pode-se citar o caso do Movimento Empresa Júnior - MEJ como exemplo desta educação empreendedora, nesta iniciativa os universitários são incentivados a abrirem e registrarem empresas juniores, assumindo a direção e a responsabilidade legal destes projetos. A partir disso estes jovens empresários prestam serviços ao mercado com a orientação de professores das Instituições de Ensino Superior na qual possuem vínculo. Destaca-se, neste processo, que além de atuarem nas empresas juniores estes jovens participam de treinamentos e encontros 


\section{DESENVOLVIMENTO DE PESSOAS EM UM MICRO EMPREENDIMENTO DO TERCEIRO SETOR: A EXPERIÊNCIA DA ADESJOVEM}

regionais, nacionais e internacionais organizados por entidades que compõem o MEJ, espaços que proporcionam oportunidade para troca de experiências e o estabelecimento de contatos profissionais.

Neste estudo será analisada a experiência da Agência de Desenvolvimento Social Jovem ADESJOVEM e a sua inserção no Movimento Empreendedor Juvenil. A instituição desenvolve projetos sociais com a juventude desde 2005, sua fundação foi idealizada por um grupo de jovens da Grande Vitória - ES, organizado em torno de um programa de rádio chamado Fala Jovem. O programa fez parte da grade de programação da FM Líder 91.1 por dois anos e buscava abrir espaço para grupos de jovens divulgarem os seus projetos. Atualmente a ADESJOVEM participa da Federação Capixaba de Jovens Empreendedores - FECAJE junto com outras 14 entidades, e realiza ações e projetos que buscam desenvolver competências empreendedoras nas juventudes. 0 objetivo do artigo é estudar a experiência da ADESJOVEM que realizou uma mudança em seu foco de atuação com a adoção de práticas de gestão de pessoas que buscam desenvolver competências empreendedoras nos seus associados e nos beneficiários de seus projetos. 0 propósito central deste trabalho, portanto, é compreender quais foram as ações realizadas, discutindo as dificuldades e aprendizagens vivenciadas no processo, a partir de entrevistas com os coordenadores e participantes dos projetos desenvolvidos no período. 0 presente estudo se enquadra na pesquisa qualitativa interpretativa, na medida em que busca compreender o contexto a partir da visão dos sujeitos envolvidos no processo. A escolha da ADESJOVEM justifica-se pela característica específica de sua fundação e de seus associados, jovens de 22 a 29 anos oriundos das diversas áreas de conhecimento e de profissões plurais, tais como advogados, administradores, pedagogos e profissionais de comunicação que atuam de maneira voluntária no desenvolvimento de projetos.

\section{Desenvolvimento De Pessoas Em Ongs}

As práticas de gestão de pessoas têm sido marcadas pela ênfase nas questões objetivas, apoiadas em ferramentas gerenciais que buscam o alinhamento dos interesses individuais aos interesses organizacionais, entendendo a diversidade de opiniões e comportamentos como problemas a serem resolvidos e controlados (SILVA; JUNQUILHO; CARRIERI, 2008). Entretanto, a questão da subjetividade dos atores organizacionais vem se apresentando como uma perspectiva e um desafio para a gestão de pessoas. Schaltegger e Wagner (2011), por exemplo, propõem um modelo para os gestores relacionarem as ações de empreendedorismo de seus colaboradores com as políticas organizacionais de gestão de pessoas. Na lógica do empreendedorismo compreende-se os objetivos organizacionais como desafios a serem alcançados, enquanto a inovação constitui-se na maneira de agir sobre os problemas cotidianos com intuito de gerar desenvolvimento social, econômico e ambiental (SCHALTEGGER; WAGNER, 2011). Os autores buscam avaliar a gestão de pessoas por meio de uma abordagem que classifica a capacidade de relacionar o empreendedorismo dos empregados com os objetivos das entidades, de modo a avaliar qual o impacto dessas práticas na mudança dos contextos que ocorrem as iniciativas institucionais.

O desenvolvimento desta capacidade relacional, segundo Kleef e Roome (2005), pressupõe o envolvimento de todos os atores no processo, acompanhado pela mudança do foco de atuação de uma perspectiva de competitividade econômica para uma gestão que considera a inovação e o empreendedorismo, como fatores que favorecem o desenvolvimento das pessoas. A gestão, portanto, "necessita tornar-se cada vez mais orientada para gerir pessoas e suas relações", o desafio, é assumir "as múltiplas realidades" e "relações" que estas pessoas estabelecem. Isto nos leva a entender a organização além das questões objetivas colocadas, e reconhecê-la como "uma 


\section{Robson Malacarne, Janette Brunstein, Margarete Dias de Brito e José Luiz Bedoni, Rodrigo Nascimento Rodrigues}

teia ou uma rede de relações" (DAVEL;VERGARA, 2009, p.307). Assim, para que as iniciativas e projetos na área de gestão de pessoas se tornem oportunidade para o desenvolvimento de competências, faz-se necessário superar a perspectiva prescritiva e proporcionar espaços de reflexão crítica sobre a realidade vivida, compreendendo suas múltiplas relações, seja no âmbito profissional ou no âmbito pessoal.

Deste modo, ao considerar o debate sobre a necessidade de desenvolver competências nos profissionais para que estes assumam uma postura empreendedora e inovadora diante dos problemas cotidianos, podem-se identificar diferentes abordagens, de acordo com a maneira que cada autor compreende a discussão. Há autores que entendem que as competências empreendedoras são atributos a serem adquiridos pelos sujeitos, enquanto há outros que defendem a necessidade de uma educação, que valorize a participação nas diversas etapas dos projetos, compreendendo as competências empreendedoras como algo a ser desenvolvido pelos coordenadores e participantes das iniciativas provocadas por organizações escolares e não escolares (FERREIRA; LOPES; MORAIS, 2006). Barreto (1998) e Dolabela (1999) concordam com essa discussão, ao afirmarem que a capacidade de empreender não é uma característica de personalidade, mas um comportamento voltado ao desenvolvimento de uma ação inovadora que precisa ser estimulada e desenvolvida. Nesse sentido, iniciativas de formação empreendedora com jovens realizadas por Organizações Não Governamentais - ONGs adquirem singular importância, pois colaboram com este processo de desenvolvimento de competências.

\section{Oportunidade De Desenvolver Competências Empreendedoras Por Meio De Projetos Sociais}

Os projetos sociais desenvolvidos por ONGs no campo da formação empreendedora, são compreendidas na literatura como Empreendedorismo Social - Esocial, Oliveira (2004) estuda as diversas concepções sobre o assunto e afirma que os atores que atuam nesta área possuem características distintas dos empreendedores de negócios pela prática de ações criadas a partir da inovação social. 0 resultado de suas iniciativas não é provocada apenas pela busca de benefícios financeiros, mas também são motivadas pela transformação da realidade, na qual o desenvolvimento social e comunitário são objetivos a serem alcançados. Neste sentido, o foco de atuação do Esocial é a busca de soluções para os problemas sociais, enquanto a ação empresarial possui como foco os resultados econômicos e o aumento de participação no mercado (MELO NETO; FROES, 2002). Diante dessas especificidades, o desenvolvimento de competências no segmento de atuação das ONGs,ocorre, por meio da participação dos associados e beneficiários das entidades nos projetos, que provocam o sujeito a reconhecer oportunidades, atuar em rede, e tomar atitudes inovadoras a partir dos cenários identificados (MAMEDE; MOREIRA, 2005).

Para cumprir com este propósito os projetos precisam envolver os jovens em trabalhos colaborativos, que possibilitem criar soluções e gerar impactos na sociedade (MILLER; WESLEY; WILLIANS; 2012). Segundo Filion (2003), a educação empreendedora desenvolvida nessas iniciativas, precisa compreender às constantes mudanças que ocorrem na sociedade de modo a realizar projetos que respondam aos desafios do cenário atual, assim, os jovens aprendem a agir a partir das dificuldades e potencialidades do local que esta sendo implantado o projeto. Deste modo, as iniciativas voltadas ao desenvolvimento de jovens empreendedores precisam identificar as habilidades que o jovem possui, demonstrando como a sua ação inovadora pode colaborar com o desenvolvimento social, econômico e ambiental, e como ele deve gerenciá-la para crescer e gerar impacto na sociedade (DORNELAS, 2001).

Esses projetos sociais desenvolvidos pelas ONGs, portanto, são fundamentais para o 


\section{DESENVOLVIMENTO DE PESSOAS EM UM MICRO EMPREENDIMENTO DO TERCEIRO SETOR: A EXPERIÊNCIA DA ADESJOVEM}

desenvolvimento de competências empreendedoras, na medida em que estimulam os jovens a serem pessoas críticas e atentas às oportunidades, capazes de transformar ideias em práticas por meio de ações inovadoras (BOLSON, 2006).0 empreendedor, neste percurso, deve receber incentivos para participar e agir sobre a realidade complexa, questionando-se sobre alternativas de ações para promover um futuro sustentável. Nesse sentido, Barth et al. (2007) discutem as condições em que o desenvolvimento de competências pode ocorrer, e mostram que as combinações de contextos formais e informais de aprendizagem favorecem o surgimento de uma nova cultura nos sujeitos, compreendendo a aprendizagemde maneira holística, preparando-os para avaliar a consequência de suas decisões para a sociedade como um todo.

Para que o sujeito desenvolva suas competências integradas as necessidades da sociedade contemporânea, a educação realizada nos projetos das ONGs não deve se restringir ao processo de aquisição de conhecimento, é necessário associar a perspectiva do empreendedorismo com a perspectiva do Desenvolvimento Sustentável - DS, nesse sentido o sujeito desenvolve a competência de reconhecer a sustentabilidade como oportunidade de integrar objetivos sociais, ecológicos e econômicos. Lans, Blok e Wesselink (2013) demonstram esta necessidade por meio de uma pesquisa com oito professores e duzentos e onze alunos, na qual se busca a opinião deles sobre empreendedorismo e a sua relação com o DS. Como conclusão deste processo, observa-se que os atores entendem o empreendedorismo como um caminho para gerar vantagem competitiva para as organizações por meio da compreensão da sustentabilidade como oportunidade de ação inovadora que gera impacto na sociedade, o que contribui para a geração de projetos e processos de negociação sustentáveis.

A discussão de Wiek, Withycombe e Redman (2011), são convergentes com as observações de Lans, Blok e Wesselink (2013) no que tange a necessidade de os beneficiários serem preparados para planejar, realizar e participar dos projetos sobre sustentabilidade, inovação e empreendedorismo, que deve ser focada na ação e na prática de solução de problemas. Por meio da revisão da literatura, os autores identificaram cinco competências chaves que devem ser consideradas neste processo: competência do pensamento sistêmico (na qual se compreende os valores e sistemas sociais); competência normativa (ao assumir a ética e justiça como pressupostos de qualquer ação); competência antecipatória (capacidade de elaborar cenários e desenvolver visões compartilhadas); competência estratégica (habilidade para identificar a viabilidade das ideias e a eficiência de sua aplicação) e competência interpessoal (liderança e cooperação em atividades que envolvem o trabalho em equipe). Como proposta de melhoria da pesquisa nesta área, estes autores sugerem o desenvolvimento de justificativas teóricas para cada competência, busca de evidências empíricas e aprofundamento do conhecimento metodológico. Uma oportunidade para discutir estas sugestões e desenvolver justificativas teóricas e empíricas que problematizam o DCEs,é a discussão sobre aprendizagem social de Elkjaer (2003), que discute as condições e contextos que favorecem o desenvolvimento de pessoas, a partir da análise de suas interações e do lócus da aprendizagem.

\section{Aprendizagem social como estratégia para o desenvolvimento de pessoas.}

A Aprendizagem Social compreende que o desenvolvimento das pessoas se relaciona a prática cotidiana do indivíduo permeada por questões formais e informais, sendo necessário integrar a prática formativa aos problemas diários do aprendiz, considerando suas diversas interações neste processo formativo. Entre os questionamentos apresentados encontra-se a crítica a Teoria da Aprendizagem Individual no que tange a sua maneira de compreender o sujeito, isolado da organização, sem reconhecer a importância do contexto no processo da aprendizagem. Em seu estudo Elkjaer (2003) revisa teorias da Aprendizagem Organizacional, destacando a proposta 
integradora da Teoria da Aprendizagem Social que valoriza os processos de participação e a interação do indivíduo como o lócus da aprendizagem. Jacobi, Granja e Franco (2006) concordam com esta proposta e defendem que a aprendizagem deve compreender as relações que se estabelecem neste processo e as implicações para os indivíduos envolvidos.

Considera-se o indivíduo como sujeito que interage com os outros, em um processo de aprendizagem, na qual o conflito com os valores e conceitos do meio que se esta inserido é constante. Elkjaer (2003) ainda destaca estratégias que estão inseridas na aprendizagem social e devem ser valorizadas nessa discussão: estratégia da negociação, estratégia da participação e estratégia da implementação. No que se refere à estratégia da negociação, valoriza-se a criação de espaços para o desenvolvimento de processos criativos de ação interativa por meio da análise de situações problemas, escolhas estratégicas e acordos com visões compartilhadas. Sugere-se como estratégia de participação nos espaços e arenas de negociação nos quais participam grupos de interesse trabalham de forma coletiva para entender a natureza de um problema comum. Assim, a estratégia de implementação é alcançada quando a aprendizagem social modifica as representações do indivíduo nas ações cotidianas que este desenvolve,capacitando-o para analisar e refletir sobre as interações e as consequências de suas práticas na sua rede de relações. Nesse sentido os indivíduos só serão capazes de lidar com as questões ambientais e sociais se forem envolvidos em ações concretas que os preparem para lidar com a complexidade do DS. 0 desenvolvimento de competências empreendedoras no nível individual, interpessoal, social ocorre por meio da prática de uma visão holística e integrada dos problemas e das soluções, sendo a educação voltada pra ação, um caminho privilegiado para a mudança na maneira de pensar e agir dos sujeitos.

A partir da análise dessas estratégias, que problematizam os contextos que favorecem a aprendizagem, observa-se que a realização de projetos nas ONGs, que se caracterize como espaço para o desenvolvimento de competências empreendedoras, necessita refletir sobre as singularidades de gestão relacionados ao tamanho do empreendimento e ao comportamento dos beneficiários atendidos nas iniciativas. No caso específico de micro empreendimentos sociais que desenvolvem projetos com as juventudes, verifica-se que a participação e o incentivo a inovação, parecem ser fatores que devem ser levados em consideração nos processos formativos. Uma gestão de pessoas que se propõe a atender essas exigências precisa associar o empreendedorismo neste processo como estratégia de ensino voltada à resolução de questões práticas que estimulem o jovem a pensar e agir sobre a sua realidade. Ciente dessas especificidades, nos próximos itens se discutirá a experiência de desenvolvimento de pessoas da ADESJOVEM, e as dificuldades e aprendizagens vivenciadas na condução de seus projetos a partir do seguinte percurso metodológico.

\section{Percurso Metodológico}

Com o intuito de compreender as mudanças e particularidades, vivenciadas a partir da adoção de práticas de inovação e empreendedorismo no desenvolvimento de pessoas de um micro empreendimento social, foi realizado um estudo qualitativo. Optou-se pela pesquisa qualitativa básica (MERRIAM, 2002) de uma micro organização não governamental como lócus da pesquisa, doravante denominada ADESJOVEM. Os sujeitos de pesquisa foram quatro membros da entidade (três integrantes da diretoria e um associado), e quatro indivíduos envolvidos em seus projetos (um educador e três jovens empreendedores). A escolha se justifica por ser um grupo que tem passado por processos de mudanças, com a participação em ações de desenvolvimento de pessoas que buscam incentivar a inovação e o empreendedorismo. A pesquisa qualitativa se justifica também pelo uso do ambiente natural como fonte de dados, no 


\section{DESENVOLVIMENTO DE PESSOAS EM UM MICRO EMPREENDIMENTO DO TERCEIRO SETOR: A EXPERIÊNCIA DA ADESJOVEM}

qual o pesquisador assume um papel fundamental neste processo, indo observar o fenômeno "no contexto em que ocorre e do qual faz parte" (GODOY, 1995). A definição dos sujeitos de pesquisa teve como critérios básicos: 1 -Coordenação e envolvimento no desenvolvimento de pessoas da ADESJOVEM 2- Participação no Programa de Incentivo a Inovação Social, Inova Jovem, e no Projeto de Educação Empreendedora, A Juventude Quer Mais. 0 tratamento de dados foi realizado com base nas seguintes proposições, resultados da revisão bibliográfica e de interpretações da pesquisa. Compreende-se que os atores organizacionais e a instituição inserem-se em uma realidade social. Este é o lugar onde o "sujeito psíquico" recria e interpreta a "rede de significados já constituídos" (JOVCHELOVICTH 1995, p. 78-79). No contexto institucional, por sua vez, verifica-se o desenvolvimento de projetos de gestão de pessoas que contemplam a discussão de empreendedorismo e inovação, com o intuito de instrumentalizar a subjetividade dos indivíduos a favor dos interesses da entidade (ENRIQUEZ, 2009). 0 sujeito, neste cenário, confronta seus conhecimentos, valores e objetivos pessoais com o "saber institucionalizado", os padrões de comportamento definidos pela organização (CAVEDON e FERRAZ, 2005). Os dados qualitativos, por sua vez, obtidos por meio da transcrição das entrevistas, foram analisados, pelo processo de categorização e codificação, inspirados na proposta de análise textual de Flores (1994). 0 critério adotado para desenvolver esse processo foi o tema que resultou em metacategorias, obtidas por meio de uma análise a priori, com base no referencial teórico. Deste modo, o tratamento dos dados foi desenvolvido com foco nas categorias Modelos de Gestão de Pessoas e Desenvolvimento de Competências Empreendedoras. Na primeira categoria buscou-se problematizar as iniciativas na área de gestão de pessoas realizadas pela ADESJOVEM com foco na teia de relações estabelecidos pelos sujeitos envolvidos, conforme preconizado por Davel e Vergara (2009). Já na segunda categoria discutiram-se os programas e projetos realizados pela ADESJOVEM, o enfoque foi analisar quais competências empreendedoras foram desenvolvidas neste percurso, utilizou-se como base as competências identificadas por Wiek, Withycombe e Redman (2011) e a discussão de Aprendizagem Social de Elkjaer (2003).

\section{Analise De Dados}

Com o objetivo de compreender como um micro empreendimento social modificou suas práticas de gestão de pessoas a partir do enfoque em inovação e empreendedorismo, foi questionado à diretoria da ADESJOVEM sobre as principais mudanças vivenciadas e implementadas por estes atores neste processo. Além disso, buscou-se discutir as principais dificuldades e aprendizagens ocorridas neste percurso e as competências empreendedoras desenvolvidas nos coordenadores do projeto e nos beneficiários dessas ações.

\section{Em Busca De Um Modelo De Gestão De Pessoas}

O estudo foi realizado na entidade ADESJOVEM, sua história iniciou-se em 2005 a partir da iniciativa de um grupo de jovens de Cariacica no Espírito Santo - ES. A micro organização não governamental atua com 20 associados de diversas formações acadêmicas interessados no desenvolvimento de projetos com a juventude. De acordo com a diretoria da entidade a missão da ADESJOVEM é a "inclusão social das juventudes por meio do desenvolvimento local e sustentável". Destaca-se que desde 2006 a entidade possui a qualificação de OSCIP- Organização da Sociedade Civil de Interesse Público, o título é oferecido pelo Ministério da Justiça as ONGs que atendem aos requisitos estabelecidos pela Lei 9.790/99. Conforme afirma Ferrarezi e Rezende (2001), as ONGs qualificadas como OSCIP podem ser compreendidas como entidades integrantes do Terceiro Setor, possuindo como característica diferenciada o interesse público de suas ações. 


\section{Robson Malacarne, Janette Brunstein, Margarete Dias de Brito e José Luiz Bedoni, Rodrigo Nascimento Rodrigues}

No início de 2013 a entidade passou a integrar a Federação Capixaba de Jovens Empreendedores - FECAJE. Atualmente a ADESJOVEM atua com projetos na Região Metropolitana da Grande Vitória no Espírito Santo. A gestão da entidade é conduzida por jovens de 18 a 29 anos, organizados em um conselho de administração (Diretoria) composto pela Presidência, Tesouraria e Secretaria, destaca-se que os profissionais destes setores atuam de maneira voluntária na entidade. Além dessa estrutura organizacional é previsto no estatuto da instituição a figura do associado, que colabora financeiramente tendo direito de participar das assembleias de decisões da entidade. Nestes espaços buscou-se desenvolver um modelo de planejamento estratégico a fim de definir o rumo da instituição, prioridades e projetos a serem desenvolvidos. Como parte deste processo, foram realizadas em torno de quatro assembleias com os associados na qual se buscou estudar a história da entidade, acertos e erros cometidos, tais como oportunidades e ameaças. Para auxiliar este percurso foi utilizado o método CANVAS de modelagem de negócios, conforme afirma o Diretor 2 da ADESJOVEM "esta estratégia de planejamento busca orientar as decisões dos atores envolvidos por meio do estudo e mapeamento da cadeia de valor da entidade", facilitando a tomada de decisões e a definição de projetos a serem desenvolvidos.

Neste caminho, um dos desafios identificados foi a necessidade de se posicionar no movimento do terceiro setor, definindo de maneira mais adequada quais são os clientes da entidade e qual o foco de sua atuação. Para responder a este desafio, analisou-se o conjunto de entidades sociais preocupadas com as causas da juventude e percebeu-se a necessidade de pensar a partir de uma nova perspectiva, na busca pela transformação do cotidiano dos jovens beneficiários. Esse novo olhar se traduziu na busca pela elaboração de projetos de desenvolvimento de competências empreendedoras para os destinatários da entidade, na qual o incentivo a inovação se colocou como estratégia para alcançar este objetivo. No entanto, apesar de contar com associados da entidade formados na área de administração, uma das dificuldades enfrentadas neste período de planejamento foi a compreensão dos termos e questões provocadas pela metodologia CANVAS. Pela percepção do grupo, a linguagem utilizada na ferramenta era adequada aos negócios que visam lucro, já para utilizar o conceito na área de projetos sociais seria necessário adaptar os termos e compreender a sua utilidade para aárea.

Apesar de o método ser simples e objetivo, esta objetividade causa um pouco de dificuldade no começo, pois as pessoas estão acostumadas a ver planejamento como uma coisa bem maçante e complicado, e por ser algo novo, enfrenta-se esta dificuldade (Diretoria 1).

Outra preocupação manifestada pela diretoria era de que o período de planejamento servisse para reconhecer a competência de cada associado de modo a colocá-la a serviço dos objetivos da entidade a partir do desenvolvimento de projetos. Como resultado deste processo de planejamento, a diretoria, junto com os associados, definiu o foco de atuação da entidade, o objetivo da ADESJOVEM seria o desenvolvimento de projetos que proporcionassem a inclusão social das juventudes por meio do incentivo ao empreendedorismo e a inovação. No entanto, devido a característica do comportamento da juventude, com socialização marcada pela flexibilidade e pluralidade de linguagens, a entidade identificou uma necessidade para que fosse alcançado este objetivo: o desenvolvimento de modelos de gestão de projetos flexíveis, na qual o próprio jovem beneficiário do projeto pudesse participar do processo de criação, desenvolvimento e realização de ideias. A identificação desta necessidade foi facilitada pelo perfil dos associados da ADESJOVEM, jovens de 15 a 29 anos, com formação multidisciplinar, interessados no desenvolvimento de competências empreendedoras. Apesar desse objetivo definido, a entidade enfrentou dificuldades para transformar em projetos estas ideias, a 


\section{DESENVOLVIMENTO DE PESSOAS EM UM MICRO EMPREENDIMENTO DO TERCEIRO SETOR: A EXPERIÊNCIA DA ADESJOVEM}

primeira lacuna identificada era ausência de material bibliográfico de elaboração de projetos que atendessem a essas especificidades, o que exigiu que a entidade buscasse criar metodologias próprias.

Como estratégia para desenvolver estas metodologias buscou-se organizar o grupo em três comissões de trabalho: Elaboração de Projetos - EP, Comunicação - Com e Organização de Eventos - OE. A comissão $E P$, buscou analisar as competências dos associados da ADESJOVEM e definir o escopo de atuação da entidade. A comissão de Com, se preocupou inicialmente com o fortalecimento da identidade visual, desenvolvimento de logomarca, fanpage e site. Já a comissão de $O E$ concentrou-se em estudar a melhor maneira de apresentar a ADESJOVEM para possíveis parceiros. A fim de manter a comunicação entre as três comissões, definiu-se que mensalmente representantes destes grupos iam se reunir com a diretoria para partilhar os avanços dos trabalhos e definir os próximos passos. Outra estratégia adotada pela entidade foi a participação de representantes em espaços de formação e troca de conhecimento como a FECAJE, que proporcionou aos associados uma compreensão do Movimento Empreendedor Juvenil, tais como suas potencialidades e dificuldades.

A participação da ADESJOVEM na FECAJE aumentou nossa rede de contatos, e a partir dai a gente pode conhecer outras entidades que também promovem 0 empreendedorismo, que é nossa linha de ação (Diretoria2).

Uma das consequências da participação da ADESJOVEM na FECAJE foi a identificação de uma dificuldade comum entre as entidades que participavam da Federação: a ausência de modelos de gestão que consideram as características singulares dos micro empreendimentos que lidam com as juventudes. Esta constatação reforçou a necessidade da diretoria da ADESJOVEM incentivar seus associados a se dedicarem a criação de modelos de desenvolvimento de pessoas alternativos, que preparem os sujeitos para lidar com estas especificidades. No entanto, apesar do interesse da diretoria da ADESJOVEM e dos associados em desenvolver um modelo de gestão flexível, que se adequasse as características do público destinatário foco da entidade, muitas dificuldades foram enfrentadas no processo. Mesmo com as reuniões mensais que pretendiam estabelecer uma partilha nas decisões sobre o rumo da entidade, conforme relatos observados, a comunicação para tomada de decisão se tornou um entrave para que a entidade conseguisse definir seus projetos prioritários, outro obstáculo identificado foi a participação dos associados nas comissões,

A gente não pode obrigar ninguém a participar pois é uma atividade voluntária, e como as pessoas tem os seus compromissos, nós tivemos dificuldades na questão de pessoas pra ajudar, o que neste ponto deixou a desejar (Diretoria 3).

Verifica-se, portanto, que a gestão de pessoas na ADESJOVEM, além de alinhar os interesses pessoais e os objetivos organizacionais, necessitou compreender as múltiplas realidades e relações que as pessoas se envolvem, a fim de desenvolver ações que mobilizam seus associados para se engajarem nos projetos da instituição, compreendida neste sentido como uma "teia de relações" (DAVEL;VERGARA, 2009, p.307). Para compreender estas relações, percebeu-se a necessidade de dedicar mais tempo para discutir as práticas de gestão e desenvolvimento de pessoas da ADESJOVEM, os associados foram envolvidos na busca desta solução, resultando na apresentação de uma proposta a diretoria. A ideia era a formação de um conselho de gestão na entidade, com frequência de reuniões semanais cujo objetivo seria encaminhar as demandas identificadas no cotidiano da ONG. Este Conselho de Gestão - CG, formado por 5 pessoas escolhidas pelos associados, buscou aprofundar a discussão sobre inovação e empreendedorismo, por meio do diálogo com entidades integrantes da FECAJE, para aprender com as iniciativas já desenvolvidas. 
O que se observou a partir disso foi que o espaço se constituiu em uma oficina de ideias para os associados, em que eles puderam aprender mais sobre o assunto e pensar alternativas para realizar as propostas da entidade. 0 marco deste momento foi o estudo realizado com o Professor Ednilson Silva Felipe, integrante do Grupo de Pesquisa sobre Inovação e Desenvolvimento Capixaba - GEPIDECA, vinculado ao Departamento de Economia da Universidade Federal do Espírito Santo - UFES, neste encontro foi possível avaliar os entraves para o desenvolvimento sustentável capixaba e a importância da inovação e do empreendedorismo neste percurso. Apesar das dificuldades enfrentadas no caminho, resultados foram alcançados pela ADESJOVEM, com o desenvolvimento de duas ações pela entidade, o Programa de Incentivo a Inovação Social, Inova Jovem, e o Projeto de Educação Empreendedora, A Juventude Quer Mais, cuja metodologia e resultados serão analisados no próximo tópico.

\section{Desenvolvimento De Competências Empreendedoras Por Meio De Projetos}

Uma das preocupações da diretoria da ADESJOVEM durante o período do planejamento era a de desenvolver iniciativas com seus associados que tivessem como base a inovação e o empreendedorismo, era fundamental que as ideias que surgissem neste processo pudessem ser aprimoradas na prática, com a participação dos jovens a serem beneficiados pelos projetos. Observa-se, portanto, que a competência empreendedora a ser apreendida nos projetos, não era considerada um atributo prévio pela entidade, mas algo a ser desenvolvida no caminho, a partir da prática, das dificuldades e das experiências enfrentadas no percurso do projeto. Neste sentido, além do associado ser incentivado a criar e desenvolver suas ideias, ele também era estimulado a problematizar a realidade social, e pensar modos e alternativas para provocar mudanças no lugar em que os projetos eram realizados.

Como exemplo desta perspectiva, pode-se citar o caso do Projeto A Juventude Quer Mais. 0 projeto surgiu a partir de uma inquietude de um dos membros da ADESJOVEM, Anselmo Rodrigues Loyola, morador do bairro Santana em Cariacica-ES. O produtor de audiovisual observou que a Escola Estadual Olímpio Cunha no bairro, estava desenvolvendo um projeto com os alunos na Disciplina de Artes, coordenado pelo Professor de Artes Visuais Evaldo Pereira. 0 objetivo da iniciativa era envolver os alunos na aula, por meio de atividades dinâmicas com oficinas de maquiagem, aprendizagem de técnicas de elaboração de roteiro, desenvolvimento de vídeos caseiros e fotos que refletissem o modo de pensar e agir do jovem, a respeito de algum problema enfrentado no bairro. 0 projeto chamou atenção de Anselmo, e despertou sobre a possibilidade de contribuir mais diretamente com a iniciativa, colocando a serviço da escola os seus conhecimentos na área de produção audiovisual.

Diante dessa inquietude realizou-se uma reunião com a Direção da Escola e o Professor Evaldo para estudar a melhor forma de efetivar a parceria com a ADESJOVEM. Na conversa o Professor Evaldo revelou um de seus objetivos: "sonho em transformar o engajamento dos alunos, e a experiência vivida por eles em um longa-metragem". 0 desafio inicial era definir o roteiro para o filme, a decisão precisava ser realizada junto com os alunos de modo a representar os anseios e as expectativas vividas por àqueles jovens. Segundo relato, isto aconteceu naturalmente, a partir de discussões em sala de aula, o Professor Evaldo havia partilhado com seus alunos as dificuldades enfrentadas por ele para alcançar o sonho de ser professor. Isto provocou estes jovens a pensar nos desafios da vida profissional, e refletir sobre a necessidade de se capacitar para realizar os seus sonhos e enfrentar as críticas das outras pessoas, foi a partir dessas discussões que nasceu o roteiro do filme Valentim. Um dos jovens participantes do projeto explica este processo, 


\section{DESENVOLVIMENTO DE PESSOAS EM UM MICRO EMPREENDIMENTO DO TERCEIRO SETOR: A EXPERIÊNCIA DA ADESJOVEM}

O filme Valentim conta a história de um jovem e as dificuldades para realizar o seu sonho, as cenas são gravadas na própria escola e procura valorizar os vários grupos de jovens que existem, buscamos refletir a realidade vivida pelos jovens que atuam como diretores e atores no filme (Participante 1).

Pode-se compreender essa iniciativa dentro da discussão realizada por Elkjaer (2003) sobre aprendizagem social, o indivíduo no Projeto A Juventude Quer Mais foi considerado um sujeito que se desenvolve na interação com os outros. A estratégia de participação foi estimulada durante o processo, na medida em que o jovem precisou se dedicar a refletir sobre um problema vivido em sua história na escola, e a partir disso realizar decisões sobre fatos, aprendizagens e dificuldades a serem relatadas no roteiro do filme a ser escrito e filmado, na qual o próprio jovem é protagonista e roteirista.

O legal de participar do filme, foi que nós aprendemos a trabalhar em grupo, a escrever uma história... aprendemos a filmar, e apesar de nossos conflitos, conseguimos colocar no papel e no filme, as nossas ideias, pois filmamos tudo na escola, a gente mesmo sendo os atores e diretores(Participante 2).

Como o trabalho foi desenvolvido em equipe, o processo foi marcado por visões compartilhadas entre os integrantes que precisaram encontrar respostas conjuntas diante das questões propostas. Entre as competências empreendedoras desenvolvidas neste percurso, pode-se destacar a competência interpessoal que envolve as atitudes da liderança e de cooperação, além da competência estratégica, fortalecida nas decisões dos jovens e dos coordenadores sobre a viabilidade das ideias e as maneiras mais eficientes para realizá-las (WIEK; WITHYCOMBE; REDMAN, 2010).

O Programa Inova Jovem, por sua vez, surgiu a partir da participação da ADESJOVEM na FECAJE, observou-se que as 14 entidades vinculadas a Federação desenvolviam iniciativas na área de empreendedorismo juvenil, na qual o próprio jovem beneficiado era o responsável por desenvolver a sua ideia, analisar as oportunidades e transformar em ação inovadora sua concepção de negócio. A ADESJOVEM começou a analisar as ações desenvolvidas por essas entidades e observou a quantidade de oportunidades geradas por essas iniciativas, pode-se citar o caso da JUNIORES, Federação de Empresas Juniores do Espírito Santo, associado a FECAJE, com foco de atuação na assessoria e desenvolvimento de Empresas Júnior- EJ, organizadas nas Faculdades do Estado. Verifica-se que cada EJ busca desenvolver competências empreendedoras específicas em seus associados, há EJs na área de comunicação, na área de consultoria organizacional, na área de engenharia, ou seja, percebe-se uma lacuna neste processo, há um série de oportunidades para os jovens colocarem sua ideia em prática e aperfeiçoarem as suas competências em determinadas áreas, no entanto, o jovem que possui este interesse, muitas vezes, não compreende a importância dessas iniciativas. A ADESJOVEM reconheceu estas dificuldades e procurou desenvolver um programa que integrasse inovação e empreendedorismo, compreendendo que,

(...) inovação é você colocar em prática algo novo ou algo que pode ser melhorado... E empreendedorismo esta relacionado a inovação, pois quando você é empreendedor você esta inovando, o empreendedor é aquela pessoa que pensa em algo diferente, em algo novo, quer ir além.. quer se destacar no mercado, por isso que o empreendedor de certa forma esta procurando sempre inovar (Diretoria 1 ).

Empreendedorismo social é você formar jovens pra atuar no dia a dia da sociedade empoderando-os, mostrando que eles são capazes de atingir seus objetivos (...), ou seja, deve-se fomentar o empreendedorismo jovem para mostrar que eles são capazes de realizar os seus sonhos (Diretoria 2). 


\section{Robson Malacarne, Janette Brunstein, Margarete Dias de Brito e José Luiz Bedoni, Rodrigo Nascimento Rodrigues}

O Programa Inova Jovem, portanto, visa atuar neste foco e se tornar uma plataforma de conhecimento organizada em um site, na qual se busca integrar e divulgar as oportunidades de inovação e empreendedorismo para as juventudes do Espírito Santo-ES. Para tornar este objetivo realidade a ADESJOVEM estabeleceu como estratégia o mapeamento das ações das entidades associadas a FECAJE e a partir disso discutir a melhor maneira para lançar o projeto. Após estudar os eventos voltados ao empreendedorismo, organizados no Estado, a diretoria entendeu como oportunidade adequada para dar visibilidade para o programa Inova Jovem, duas atividades, a Semana Nacional de Ciência e Tecnologia e a Semana Global de Empreendedorismo.

A Semana Nacional de Ciência e Tecnologia no ES foi realizada na área de eventos da Praça do Papa no município de Vitória, e mobilizou em torno de cem mil pessoas, a ação da ADESJOVEM no evento envolveu exposição em estande próprio, realização do Seminário Inova Jovem, e produção de vídeos. Conforme afirma o Diretor 1,

As atividades nestes diversos espaços buscaram envolver os jovens e participantes presentes por meio de uma pergunta provocadora: 0 que você pode fazer pra mudar a sua realidade? Ao visitar o estande o jovem era estimulado a pensar sobre as suas responsabilidades na mudança de sua história, na realidade de seu bairro, na condição de sua escola e na qualidade da prestação de serviços públicos em geral (Diretoria 1).

Além disso, o jovem era provocado a refletir sobre os passos necessários para colocar suas ideias de negócios em prática a partir dos desafios e problemas identificados, a necessidade de inovar neste percurso foi identificada como uma competência a ser desenvolvida para criarem alternativas e superar essas dificuldades. O Seminário Inova Jovem, por sua vez, contou com a palestra do empresário Francisco Neto, que buscou contar sua história aos jovens, desde a época de camelô até a consolidação de sua rede de lojas de calçados Los Neto. Durante a palestra, os participantes fizeram vários questionamentos ao empresário sobre as dificuldades enfrentadas e as atitudes e decisões tomadas diante destes desafios. Para não perder as ideias geradas no estande e no seminário foram registradas as discussões em um vídeo que foi publicado no site inovajovem.com, que continua funcionando, procurando demonstrar iniciativas que estimulem as juventudes a adotarem uma prática empreendedora e inovadora no seu cotidiano. Neste sentido a Semana Nacional de Ciência e Tecnologia,

(...) foi um espaço na qual a ADESJOVEM foi vista por múltiplos públicos, desde jovens estudantes, jovens trabalhadores, jovens empreendedores que já tem o seu negócio, grandes empresas e também possíveis parceiros. A importância da participação foi nesse sentido mesmo, do Programa Inova Jovem ser divulgado pra sociedade! (Diretoria 3)

Outra ação realizada para dar visibilidade ao Programa Inova Jovem foi a participação na Semana Global de Empreendedorismo, que se constitui em um movimento composto por um série de atividades, como palestras e competições, que buscam incentivar e fortalecer a cultura empreendedora. No Espírito Santo as ações foram promovidas pela FECAJE, e a participação da ADESJOVEM no processo, caracterizou-se pela organização de um encontro com os Prefeitos da Região Metropolitana da Grande Vitória, composta pelos Municípios de Vitória, Cariacica, Fundão, Guarapari, Serra e Vila Velha. Na atividade foram apresentados aos Prefeitos as ações realizadas por todas as entidades associadas a FECAJE, o intuito era demonstrar a importância do Movimento Empreendedor Jovem e o seu papel na inovação e no desenvolvimento sustentável capixaba, para que, a partir deste primeiro contato, fosse possível a realização de um projeto em parceria com as prefeituras nos municípios. 
Foi muito bom participar deste encontro, tivemos a oportunidade de apresentar nossas ideias e ações, e junto com os prefeitos conseguimos criar perspectivas, pensar cenários para a juventude empreendedora do ES, ou seja, conseguimos pensar soluções para os problemas concretos que afligem os jovens da Grande Vitória (Participante3).

Neste processo, os atores envolvidos desenvolveram a Competência Antecipatória, pois se dedicaram a identificar cenários a partir de visões compartilhadas sobre as ações que devem ser realizadas para incentivar o empreendedorismo e a inovação nas juventudes (WIEK; WITHYCOMBE; REDMAN, 2011).Observa-se que o desafio para a realização de projetos na ADESJOVEM estão relacionados a participação dos associados e dos beneficiários nos projetos, na qual o sujeito é provocado a refletir sobre quais posturas são mais adequadas a assumir diante das dificuldades enfrentadas, neste caso a competência normativa é desenvolvida na prática cotidiana dos sujeitos, que assumem a ética e a justiça como pré-requisitos de sua ação. A oportunidade do desenvolvimento de competências empreendedoras, portanto, ocorre quando os envolvidos compreendem que a sua ação inovadora colabora para a solução de problemas concretos, que fazem parte de sua história na escola, na família, no bairro, no local de trabalho, e nos diversos âmbitos de sua vida. A corresponsabilidade neste processo promove uma mudança na cultura dos atores, incentivando-os a agir diante da realidade complexa, buscando alternativas para promover o futuro sustentável e a busca de soluções nas dimensões sociais, ambientais e econômicas do desenvolvimento (LANS; BLOK; WESSELINK, 2013). A partir do momento que os sujeitos envolvidos adquirem essa visão holística da realidade e desenvolvem a competência do pensamento sistêmico, reconhece-se com mais facilidade as oportunidades, e define-se melhor as decisões diante dos cenários identificados. Neste sentido a aprendizagem social experimentada nestas iniciativas qualificam os sujeitos para serem protagonistas na construção da sociedade sustentável, na medida em que a educação voltada para a ação, proporciona espaços críticos para o jovem colocar a sua ideia em prática, refletindo e agindo a partir das dificuldades encontradas (JACOBI; GRANJA; FRANCO, 2006).

\section{Considerações Finais}

Neste estudo buscou-se compreender a experiência de desenvolvimento de pessoas da ADESJOVEM, que estimulou práticas de inovação e empreendedorismo em seus associados e beneficiários, por meio da realização de projetos como o Programa de Incentivo a Inovação Social, Inova Jovem, e o Projeto de Educação Empreendedora, A Juventude Quer Mais. Neste percurso a busca por um modelo de gestão de pessoas adequado para o micro empreendimento social envolveu mais do que um alinhamento de objetivos, mas o desenvolvimento de iniciativas com base no estudo das teias de relações que envolvem os associados e os beneficiários dos projetos realizados. Relatou-se nas entrevistas a preocupação com a valorização das ideias sugeridas durante o processo, de modo a proporcionar oportunidades para o desenvolvimento de competências empreendedoras, resultado da participação dos sujeitos nas diversas etapas, desde a elaboração até a execução dos projetos. Para alcançar este objetivo, destaca-se as iniciativas do planejamento estratégico participativo e o desenvolvimento dos projetos propostos pelos próprios associados, discutidos neste trabalho.

Essas iniciativas priorizaram o desenvolvimento dos sujeitos por meio da interação com os outros, compreendendo a teia de relações e realidades que envolvem o cotidiano das pessoas. Neste caminho, as estratégias de ensino experimentadas nos projetos, procuraram envolver os sujeitos por meio de questões provocativas sobre a realidade vivida em sua história. Enfatiza-se que a aprendizagem vivenciada nestes espaços foi marcada pela prática e experiência, sendo proporcionado ao jovem a chance de refletir sobre a sua ideia, observando e buscando soluções para as dificuldades encontradas. O trabalho colaborativo fez parte destes projetos e 
demonstrou aos participantes a importância de lidar com a pluralidade de opiniões para realizar as suas ideias. A partir destas constatações, buscou-se sintetizar as práticas de desenvolvimento de pessoas e as estratégias de ensino experimentadas pela ADESJOVEM, as aprendizagens e dificuldades enfrentadas, e as competências empreendedoras desenvolvidas, por meio do quadro abaixo:

\begin{tabular}{|c|c|c|}
\hline $\begin{array}{l}\text { Ações de Desenvolvimento de } \\
\text { Pessoas e Estratégias de Ensino } \\
\text { experimentadas. }\end{array}$ & $\begin{array}{l}\text { Aprendizagens e Dificuldades } \\
\text { encontradas }\end{array}$ & $\begin{array}{l}\text { Competências } \\
\text { Empreendedoras } \\
\text { desenvolvidas }\end{array}$ \\
\hline $\begin{array}{l}\text { - Planejamento estratégico } \\
\text { participativo } \\
\text { - } \quad \text { Criação de comissões de } \\
\text { projetos temáticos } \\
\text { (comunicação, elaboração de } \\
\text { projetos e eventos) } \\
\text { - Conselho de Gestão } \\
\text { - } \text { Desenvolvimento de projetos } \\
\text { com foco em inovação e } \\
\text { empreendedorismo (Inova } \\
\text { Jovem e A Juventude Quer } \\
\text { Mais) }\end{array}$ & $\begin{array}{l}\text { Aprendizagens: } \\
\text { - } \quad \text { Participação em projetos } \\
\text { colaborativos favorecem o } \\
\text { desenvolvimento de } \\
\text { competências } \\
\text { empreendedoras. } \\
\text { A gestão de pessoas deve ir } \\
\text { além do alinhamento de } \\
\text { interesses pessoais e } \\
\text { organizacionais, e se } \\
\text { concentrar em compreender } \\
\text { a teia de relações e as } \\
\text { realidades que envolvem o } \\
\text { cotidiano das pessoas. } \\
\text { O incentivo a inovação e ao } \\
\text { empreendedorismo } \\
\text { favoreceu o engajamento } \\
\text { dos associados nos projetos } \\
\text { da ADESJOVEM. } \\
\text { - } \quad \text { Disponibilidade de tempo } \\
\text { dos voluntários para } \\
\text { participação e realização dos } \\
\text { projetos. } \\
\text { gestão de pessoas que } \\
\text { considerem as } \\
\text { especificidades de micro } \\
\text { empreendimentos do } \\
\text { terceiro setor. } \\
\text { Dificuldades: }\end{array}$ & $\begin{array}{ll}\text { - } & \text { Pensamento } \\
& \text { Sistêmico (valores e } \\
\text { sistemas sociais) } & \text { Competência } \\
\text { Interpessoal } \\
\text { (liderança e } \\
\text { cooperação). } \\
\text { Competência } \\
\text { Estratégica } \\
\text { (viabilidade e } \\
\text { eficiência) } \\
\text { Competência } \\
\text { Antecipatória } \\
\text { (cenários e visões) } \\
\text { Competência } \\
\text { Normativa (ética e } \\
\text { justiça) } \\
\text { Competência para a } \\
\text { inovação social } \\
\text { (criação de } \\
\text { alternativas para os } \\
\text { problemas sociais). }\end{array}$ \\
\hline
\end{tabular}

Quadro 1: Processo de Desenvolvimento de Pessoas na ADESJOVEM.

Fonte: Elaboração dos autores a partir da referência teórica e da análise de dados.

Como exposto no quadro acima e discutido durante o artigo, com a participação dos associados e dos beneficiários da ADESJOVEM nos projetos, estes sujeitos foram expostos a contextos que favoreceram o desenvolvimento de competências empreendedoras. Isto se tornou possível devido às dinâmicas realizadas nas atividades, que provocam o exercício da liderança e a cooperação na busca pelos objetivos. Neste processo, a tomada de decisões foi uma rotina, na qual se exercitou a competência estratégica, que é desenvolvida por meio da análise da viabilidade das ideais e a eficiência ou não de sua aplicação. A competência do pensamento sistêmico e a competência antecipatória, por sua vez, também foram aprimoradas nos espaços dedicados para o planejamento, nas discussões das comissões e nas ações realizadas em parceria com a FECAJE e os Prefeitos da Grande Vitória. Neste sentido, a capacidade de envolver 
diversos atores nos debates, sobre as possíveis parcerias para incentivar o desenvolvimento da inovação e do empreendedorismo nas juventudes, proporcionou oportunidade para compartilhar visões sobre as ações a serem realizadas diante da realidade complexa, o que favoreceu o desenvolvimento da competência normativa. Destaca-se, ainda, que no processo de desenvolvimento de pessoas da ADESJOVEM, a competência da inovação também foi aprimorada. Isto foi estimulado pela ausência de modelos de soluções para as dificuldades vividas neste micro empreendimento social, o que provocou os sujeitos a inovar, e a criar alternativas para agir diante da rede de relações e interesses, manifestados durante a realização dos projetos e ações da entidade.

Assim, espera-se que este estudo tenha contribuído para o avanço das reflexões sobre a gestão no terceiro setor, de modo específico no que se refere ao desenvolvimento de competências empreendedoras. Como discutido, verificou-se a necessidade de se desenvolver metodologias próprias para a gestão de pessoas nos micro empreendimentos sociais, que considerem suas especificidades e desafios, como por exemplo, a mobilização de voluntários e o seu engajamento nos projetos desenvolvidos pelas ONGs. A análise dos dados demonstra que o incentivo a inovação e ao empreendedorismo são estratégias que favorecem a superação destas dificuldades, principalmente quando associadas a projetos que valorizam a participação e o compartilhamento de visões, nas diversas etapas de seu desenvolvimento. Sugere-se que estudos futuros pesquisem outras metodologias e soluções criadas por micro empreendimentos do terceiro setor nesta área, já que observa-se uma lacuna neste campo de estudo, o que revela a necessidade de mais aprofundamentos teóricos e empíricos, favorecendo o avanço em seu estado da arte.

\section{Referências}

BARRETO, L. P. Educação para o empreendedorismo. Salvador: Escola de Administração de Empresas da Universidade Católica de Salvador, 1998.

BOLSON, E. Educação Empreendedora. Disponível em: <http://www.administradores.com.br/artigos/educacao_empreendedora>. Acesso em: 05 de dez. de 2012.

BARTH, M.; GODERMANN, J.; RIECKMANN, M.; STOLTENBERG, U. Developing key competencies for sustainable development in higher education. International Journal of Sustainability in Higher Education, v. 8, n. 4, p.416-430, 2007.

CAVEDON, N.R.; FERRAZ, D.L.S. Representações Sociais e Estratégias em Pequenos Comércios. RAE- eletrônica. $\quad$ v. 4, n. 1, jan./jun. 2005 . Disponível em: $<$ http://www.rae.com.br/eletronica/index.cfm?FuseAction=Artigo\&ID=2036\&Secao=FOR.GEST .$B \&$ Volume $=4 \&$ Numero $=1 \& A n o=2005>$. Acesso em: 05 de nov. de 2005 .

DAVEL, E; VERGARA, S.C; Subjetividade, sensibilidades e estratégias de ação. DAVEL, Eduardo; VERGARA, Sylvia Contant. Gestão com Pessoas e Subjetividade. São Paulo: Atlas, p. 305-313, 2009. 


\section{Robson Malacarne, Janette Brunstein, Margarete Dias de Brito e José Luiz Bedoni, Rodrigo Nascimento Rodrigues}

DOLABELA, F. Oficina do empreendedor. São Paulo: Editora de Cultura, 1999.

DORNELAS, J. C. A. Empreendedorismo: transformando ideias em negócios. Rio de Janeiro: Campus, 2001.

ELKJAER, B. Social learning theory: learning as participation in social process. In: EASTERBYSMITH, M., LYLES, M.A. (Ed.). The Blackwell handbook of organizational learning and knowledge management. Oxford: UK: Blackwell Publishing, p. 38-53, 2003.

ENRIQUEZ, E.; Interioridade e organizações. DAVEL, E; VERGARA, S. C. Gestão com Pessoas e Subjetividade. São Paulo: Atlas, p.173-186, 2009.

FERRAREZI, E.; REZENDE, V. Organização da sociedade civil de interesse público - OSCIP : a lei 9.790 como alternativa para o terceiro setor. Brasília: Comunidade Solidária, 2001.

FERREIRA, A.J.D; LOPES, M.A.R; MORAIS, J.P.F. Environmental management and audit schemes implementation as an educational tool for sustainability. Journal of Cleaner Production, n.14, p. 973-982, Fev. 2006.

FILION, L. F.; LAFERTÉ, S. Carte routière pour um Québec entrepreneurial. Montreal: HEC, 2003.

FLORES, J. F. Análisis de datos cualitativos: aplicaciones a la investigación educativa. Barcelona: PPU, p. 7-107, 1994.

GODOY, A. S.; Introdução a pesquisa qualitativa e suas possibilidades. Revista de Administração de Empresas, v.35, n.2, p.57-63, Mar./Abr.1995a.

GODOY, A.S.; Pesquisa Qualitativa - Tipos fundamentais. Revista de Administração de Empresas, v.35, n.2, p.20-29, Mai./Jun. 1995b.

GROPPO. L. A. Juventude: ensaios sobre sociologia e história das juventudes modernas. Rio de Janeiro: DIFEL, 2000.

JACOBI, P.R; GRANJA, S.I.B.; FRANCO, M.I. Aprendizagem Social: práticas educativas e participação da sociedade civil como estratégias de aprimoramento para a gestão compartilhada em bacias hidrográficas. São Paulo em Perspectiva, v. 20, n. 2, p. 5-18, abr./jun. 2006.

JOVCHELOVITCH, S.Textos em Representações Sociais. 8ª Ed. Petrópolis, RJ: Vozes, 1995.

KLEEF, J.A.G.; ROOME. N.J. Developing capabilities and competence for sustainable business management as innovation: a research agenda. Journal of Cleaner Production, v.15, p. 38 a 51, 2007.

LANS, T.; BLOK, V.; WESSELINK, B. Renate Wesselink Learning apart and together: towards an integrated competence framework for sustainable entrepreneurship in higher education. Journal of Cleaner Production, xxx, p 1-11, 2013.

MAMEDE, M. I. de B.; MOREIRA, M. Z. Perfil de competências empreendedoras dos investidores portugueses e brasileiros: um estudo comparativo na rede hoteleira do Ceará. In: Enanpad: 
2005. Anais. Brasilia/DF.

MELO NETO, F. P.; FROES, C. Empreendedorismo social: a transição para a sociedade sustentável. Rio de Janeiro: Qualitymark, 2002.

MERRIAM, S. B. Qualitative research in practice. Examples for discussion and analysis. San Francisco: Jossey-Bass, 2002.

MILLER, T.L; WESLEY, C.L;WILLIAMS; D.E. Academy of Management Learning \& Education. Educating the Minds of Caring Hearts: Comparing the Views of ractitioners and Educators on the Importance of Social Entrepreneurship Competencies. v. 11, n. 3, p. 349-370, 2012.

OLIVEIRA, E.M. Empreendedorismo social no Brasil: atual configuração, perspectivas e desafios - notas introdutórias. Rev. FAE, Curitiba, v.7, n.2, p.9-18, jul./dez. 2004.

RAMOS, A. G. A nova ciência das organizações: uma reconceituação da riqueza das nações. $2^{\circ}$ edição. Rio de Janeiro: Editora da Fundação Getulio Vargas, 1989.

SCHALTEGGER, S.; WAGNER, M. Sustainable Entrepreneurship and Sustainability Innovation: Categories and Interactions. Business Strategy and the Environment, v.20, p. 222-237,2011.

SILVA, A.R.L.; JUNQUILHO, G.S.; CARRIERI, A.P. Políticas de RH: Instrumentos de Consenso e Ambiguidade. RAC, Curitiba, v. 12, n. 1, p. 11-34, Jan./Mar. 2008.

WIEK, A.; WITHYCOMBE, L; REDMAN, C. Key competencies in sustainability: a reference framework for academic program development. Research System for Sustainability Science, United Nations University, 2011. Disponível em:

<http://www.e3washington.org/upload/profile/resources/file-268.pdf>. Acesso em: 20 de jan. de 2014. 